\title{
Given the Time and the Money to Think, Consumers will Rely more on Intuition, Sensations, and Emotions, rather than Rationale, to Decide
}

\author{
Francisco J. Quevedo \\ Lubin School of Business, Pace University, New York \\ ${ }^{*}$ Corresponding author email: fquevedo@pace.edu
}

Received: 14 June 2019 / Revised: 06 July 2019 / Accepted: 17 July 2019 / Published: 18 July 2019

\begin{abstract}
The weight of intuitive, sensory, emotional, and rational criteria in consumer decision making has been debated for ages, we could say. The rational model dominated Marketing all through the $20^{\text {th }}$ Century, but on the onset of the new millennium, the case has been made, and strongly so, for a more integrated view of consumer behavior, that allows for, if you will, the rationalization of emotional conducts. In this paper, we present the results of an experiment that shows that purchases are not all that rational, and that -indeed-given the time, and the money to think it through, consumers will paradoxically rely more on their intuition, their emotions and sensations, that is, on feelings over rational criteria, to arrive at a purchase decision. This experiment manipulated two variables, time and money, using a convenience sample of undergraduate students in three classes of Pace University, NY, to apply the same situational questionnaire under two different hypothetical scenarios, where one is similar to the students' current situation.

Keywords: Rationality, rationalization, intuition, emotion, sensations, feelings, decisions, decision-making, resources, time and
\end{abstract} money.

\section{Introduction}

The millenary debate between Aristotle and Epicurus seems to be coming to an end. The "rational animal" has been pitted against modern man, and his eternal "search for pleasure and the avoidance of pain", and, apparently, the rational animal has lost, the hedonist wins, as Srinivasan (1987) would suggest. Historically, logic dominated consumer research throughout the 20th Century. Indeed, Nicosia's (1966) and Howard \& Sheth (1969) models epitomized rationality. However, later studies have found that humans follow their intuition in making decisions; that emotions prevail over rationale; and that -in the end-rationalization most times only serves to justify what otherwise would have been intuitive decisions, carried more by "feeling" than by "rationality". Morin and Renvoise (2018) state that persuasion is not controlled by the rational brain, but rather, he might suggest that it is MacLean's (1973) primal brain which dominates the process. Sweldens (2018) equates the appeal of a product or brand to what he calls "evaluative conditioning", when he speaks about the consumer's association of paired stimuli by sheer repetition and found this process to be largely unconscious. Li (2019) would add that emotional appeals are not homogeneous, nor do they generate similar responses across different consumption scenarios, and Bergqvist and Cowan (2018) state that the ensuing consumer experience is not reason-responsive. So, it would seem that rationality is out, at least insofar as we have traditionally defined rationality as pure logic, devoid of emotional and sensory considerations.

Indeed, would say Rytel (2010), who found that consumers are not faithful to brands, as such, but to images and symbols, and to the sensations they generate, thereby bringing sensory appeals into the theoretical mainstream. Lees-Maffei (2019) calls that "semiotics in action", while Shelley (2019) speaks of "the amygdala era", bringing us back to the concept of the Triune Brain.

Working on the shoulders of previous scientific works, we studied how much intuitive, sensory, emotional, and rational criteria truly weigh on important consumer decisions, experimenting on a trial basis with a sample of students from three undergraduate classes at Pace University, NY, who were presented with six identical questions regarding one particular purchase situation, buying a car, where only time and money, Copyright (C) 2019. The Author(s). Published by AIJR Publisher.

This is an open access article under Creative Commons Attribution-NonCommercial 4.0 International (CC BY-NC 4.0) license, which permits any non-commercial use, distribution, adaptation, and reproduction in any medium, as long as the original work is properly cited. 
Given the Time and the Money to Think, Consumers will Rely more on Intuition, Sensations, and Emotions, rather than Rationale, to Decide or credit available, were manipulated. Our results prove that given the latitude, decisions will be progressively more emotional than rational.

\section{Literature Review}

Models that assume a rational process of persuasion dominated marketing as a discipline during the $20^{\text {th }}$ Century, said Block, Schultz, Breiter, Blood, Calder, Chamberlain and Fengqing (2015); problem recognition, information search, logical evaluation, and purchase decision, in a few words, had been taken to mean a rather cold, calculating process of deduction; but, really, now, are consumers always all that rational? That is the question Shugan (2006), and Steven (2006) quite literally asked. MacLean (1973) tracked the evolution of the human brain, and correlated behavior with three distinct criterion centers: the reptilian brain, our oldest, which commands intuitive behavior, the limbic brain, which holds emotional memory, and the neo-cortex, which processes rational thought. According to his studies, decisions may be rational, emotional, or intuitive, or the mixed product of all criteria. Zajonc and Markus (1982) pointed to the importance of the emotional content in the decision-making processes, which had been, until then, sidelined as "irrational". Scrull (1984) studied the effects of moods on judgment. Chanutl (2011), and Valente (2012), extended the considerations of Simon's (1987) theory of "bounded rationality" to consumer decision making, suggesting that we are not that rational. Fetterman and Robinson (2013) found that decisions balance emotional vs. rational criteria; while Kahneman (2003) posited that even when faced with our most important decisions, emotion, not reason, guides our decision process. He received the Nobel Prize in Economics 2002 for his findings on human behavior.

Without a doubt, we would say, ironically perhaps. Eser, Isin, Bahar and Tolon (2011), found that unconscious mental processes are major influences in peoples' deliberations. Lake, Carlson, Rose and Chlevin-Thiele (2019) consider trust an intuitive conclusion. Indeed, Bergqvist and Cowan (2018) found that experiences are not reason-responsive. Kavalali (2015) suggested clearly that actions and decisions may have nothing to do with conscience, but with neurochemical dynamics. Roeser (2010) presented empirical research that supports the idea that people follow their initial intuitions, and "gut feeling", in decisionmaking, and Denes-Raj and Epstein (1994) said they do so sometimes "against their better judgment", suggesting, with a bit of irony, that intuition is -again- irrational, while Bettman, Luce and Payne (1998) suggested that consumers tend to choose based on pre-established preference sets, and many times end up merely satisficing, a term coined by Simon (1987). Even West, Brockett and Golden (1997) talk about intuition in their neural networks predictive model of consumer choice. Cian, Krishna and Schwartz (2015) say that emotion and rationality are fundamental elements of human life, but that, as abstract concepts, they are often difficult to define and grasp. Batoni (2015) suggests that, while the brain is a neurological system, the mind is a system of meanings that makes sense of our senses, thus separating rationality and physiology, and thoughts from feelings. McMillan (2014) said that mental processes are generated by the brain, but in a broadly distributed fashion, inaccessible to direct measurement. They all seem to point to a black box. Paradoxically, it would seem, we are still trying to understand the human mind.

In terms of time and money, Saini and Monga (2008) showed that consumers used more anchoring heuristics mechanisms in time than in money. A dollar is much easier to cognitively process than time, they said. Lee, Lee, Bertini, Zauberman and Ariely (2015) found that money elicits rational reactions, while time generates emotions instead. They say that priming on money vs. time will elicit different behaviors downstream, including product attitudes. Indeed, Mogilner (2010) had analyzed the relationship between money and happiness, and proposed that time relates to happiness more appropriately. Vohs and Faber (2003) would consider time and money as resources in their theory of self-regulation, though they did not link it precisely to emotionality, or to the effect of the senses and intuition in purchase decisions.

These studies lead us to question that concept of rationality that defines it as an absolutely logical process, insofar as it excludes what we would call perfectly rational emotional considerations in decision making. We aim to prove that when given the time to think, consumers will not "think", that is, they will decide on the basis of intuitive and emotional criteria instead. 


\section{Hypotheses}

Drawing on MacLean (1973), who tied human behavior to the brain's natural evolution, stemming from the intuitive; Denes-Raj and Epstein (1994), and Roeser (2010), who proposed that consumers "follow their gut feeling" in making decisions; Kahneman (2003), who found that even in our most important decisions in life, emotion, not rationality, guides the process; Shugan (2006), and Steven (2006), who asked if consumers are "rational"; Eser et al (2011), who found that unconscious mental processes are major influences in peoples' deliberations; Fetterman and Robinson (2013), who proved that decisions balance emotional vs. rational criteria; Kavalali (2015), who even suggested that decisions may have nothing to do with conscience; McMillan (2014), and Batoni (2015), who separated the physiological processes from the mental dynamics, and Lee, Lee, Bertini, Zauberman and Ariely (2015) who highlighted the different behavioral reactions to time vs. money, but considering these variables together, as resources to test their effect on self-control, following Vohs and Faber's (2003) concept; and although Chang and Pham (2013) related emotional content in decision making to the immediacy of the outcome, we would posit the following hypotheses, starting with the null:

H0: $\quad$ Consumer decisions are absolutely rational, and consistently so over time, and money.

H1: Given the time and the money, the consumer will decide based mostly on intuitive, sensory, and emotional criteria.

The following research questions guided our research:

- What criteria do consumers consider when making an important purchase?

- Given time and budgetary constraints, which of these criteria prevail in their decisions, and/or which ones lean toward the rational vs. the irrational?

- Time and budgetary constraints removed, which criteria will now prevail in their decision?

- Which might be the moderating factors?

\section{$4 \quad$ Research Methodology}

We carried out one trial experiment, using close to one hundred Pace University students ( $\mathrm{n}=86$ ) attending three classes Tue-Thu between 09:00am and 12:00, and Mon-Wed between 01:00pm and 03:00pm, who were presented with two hypothetical purchase situations:

I. Buying a car upon graduation, without their parents' help, to get around, and go to work, against...

II. Purchasing a car once they have built up their income, job experience, savings, and a good credit score (see attached questionnaire).

Thusly, in essence, we manipulated two variables, "time" and "money", or credit, in lieu of cash, maintaining the purchase decision the same: to buy a car.

To choose appropriate terms to measure intuitive and emotional criteria, we reviewed existing tools, and found than Phillips, Fletcher, Marks and Hine (2016) state that thinking styles are assessed with self-report scales that generally demonstrate high internal consistency and test-retest reliability, and suggest that the Rational Experiential Inventory (REI; from Epstein et al., 1996) has been used more frequently than other thinking style inventories and is arguably the most reliable across its different versions.

The authors describe the Preference for Intuition and Deliberation (PID; taken from Betsch, 2004) scale, which consists of 18 self-reported items; 9 for intuitive thinking, determined with agree - disagree statements as "I listen carefully to my deepest feelings"; and 9 for deliberate, measured with proposals like "Before making decisions I usually think about the goals I want to achieve" on a 5-point Likert scale.

We considered Harmon-Jones and Bastian's (2016) Discrete Emotions Questionnaire (DEQ), a selfreported measurement instrument that includes emotions labeled as "basic" by prominent emotion theories, such as anger, disgust, fear, anxiety, sadness, and joy, using story-prompts that trigger feelings, which the subjects are asked to describe. Emotions are assessed through word-association. 
Given the Time and the Money to Think, Consumers will Rely more on Intuition, Sensations, and Emotions, rather than Rationale, to Decide

Buck, Anderson, Chaudhuri and Ray (2004) present two models, the Affect-Reason-Involvement (ARI), and the Communication via Analytic and Syncretic Cognition Scale (CASC). The ARI model, the authors say, aims to conceptualize and measure how attitude objects and messages are cognitively processed, and the level of involvement as defined by the depth and quality of this processing. It provides a representation of the depth of thought and feeling about an object or message, however, it does not in itself represent evaluation: whether the object or message is liked or disliked. Specific emotions can be assessed by the CASC scale, which can be modified to fit those emotions relevant to a specific area of study.

We presented the subjects with six identical questions that represented the following criteria for either situation:
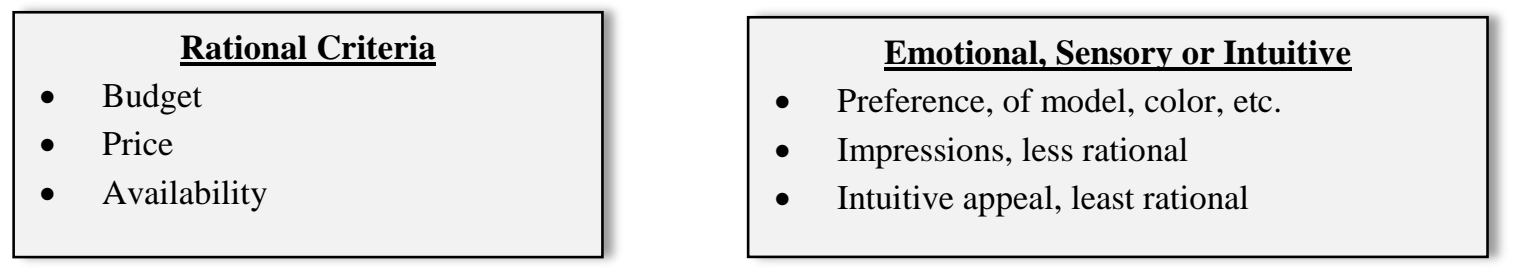

The subjects were motivated to respond by extra credit but were not obligated. The final response rate was over $50 \%$, with some incomplete items being excluded.

\section{Statistical Methods and Tests}

Regression analysis was applied to compare means of paired criteria, one by one, between the two purchase situations, a car now, with limited resources, vs. a car later, with sufficient time and money. These criteria intended to weigh, for instance, whether the subjects would buy the car they need vs. the car they want, upon graduation vs. later in their professional careers. Similarly, they weighed whether they would buy a preowned car, or a new car, now or later on. Then they asked how price or availability is taken into account, looks and style, and lastly, how much does intuition weigh in the process. On a Likert scale of 1 to 7 , higher scores reflect rationality, criteria dealing with need, budget, price, availability, while scores below 3.5 would lean toward emotionality, intuition, and sensory considerations, such as style, and quite bluntly "following the nose". T-Tests rated the significance of the variation in the means for each criterion.

\section{Results}

As can be seen in the following Table 1, means scores drop significantly between purchase scenario \# 1 , buying a car upon graduation, and purchase scenario \# 2, buying a car later on, when money or credit, and time, are more favorable, showing a clear shift from rationality toward emotionality and other "less rational" criteria.

Table 1: Paired Samples Statistics

\begin{tabular}{|c|c|c|c|c|c|}
\hline Pair & Scenario & Mean & N & Std. Dev. & Std. Error of Mean \\
\hline \multirow{2}{*}{ Pair 1 } & Purchase 1 on Need & 6.02 & 86 & 0.975 & 0.150 \\
\cline { 2 - 6 } & Purchase 2 on Need & 3.02 & 86 & 1.689 & 0.261 \\
\hline \multirow{2}{*}{ Pair 2 } & Purchase 1 on Cost & 5.60 & 86 & 0.964 & 0.149 \\
\cline { 2 - 6 } & Purchase 2 on Cost & 3.02 & 86 & 1.334 & 0.206 \\
\hline \multirow{2}{*}{ Pair 3 } & Purchase 1 on Avail. & 6.24 & 86 & 1.165 & 0.180 \\
\cline { 2 - 6 } & Purchase 2 on Avail. & 4.60 & 86 & 1.668 & 0.257 \\
\hline \multirow{2}{*}{ Pair 4 } & Purchase 1 on Used & 5.74 & 86 & 1.563 & 0.241 \\
\cline { 2 - 6 } & Purchase 2 on Used & 2.76 & 86 & 1.665 & 0.257 \\
\hline \multirow{2}{*}{ Pair 5 } & Purchase 1 on Style & 3.76 & 86 & 1.365 & 0.252 \\
\cline { 2 - 6 } & Purchase 2 on Style & 2.12 & 86 & 1.131 & 0.174 \\
\hline \multirow{2}{*}{ Pair 6 } & Purchase 1 on Logic & 3.38 & 86 & 1.577 & 0.243 \\
\cline { 2 - 6 } & Purchase 2 on Logic & 2.36 & 86 & 1.543 & 0.238 \\
\hline
\end{tabular}


Francisco J. Quevedo, Adv. J Social Sci.; Vol. 6 Issue 1, pp: 38-47, 2020

Graph 1 below allows us to visualize the shift from what would be called a rational decision, when time and money is scarce, to a more emotional, sensory and intuitive purchase, when time and money are amply available. Need, cost, availability, new vs. used, looks and style, and pure logic all jump from the rational side of the scales, to the realm of the emotional, sensory and the intuitive.

As can be seen in the following Table 2, the variations in means, by criterion, show to be, without exception, statistically significant, leading us to reject the null hypothesis, $H o$, which stated that consumer decisions are absolutely rational, and consistently so over time, and money, and to claim instead that given the time, and the money, consumer decisions will be more intuitive, and emotional, than rational.

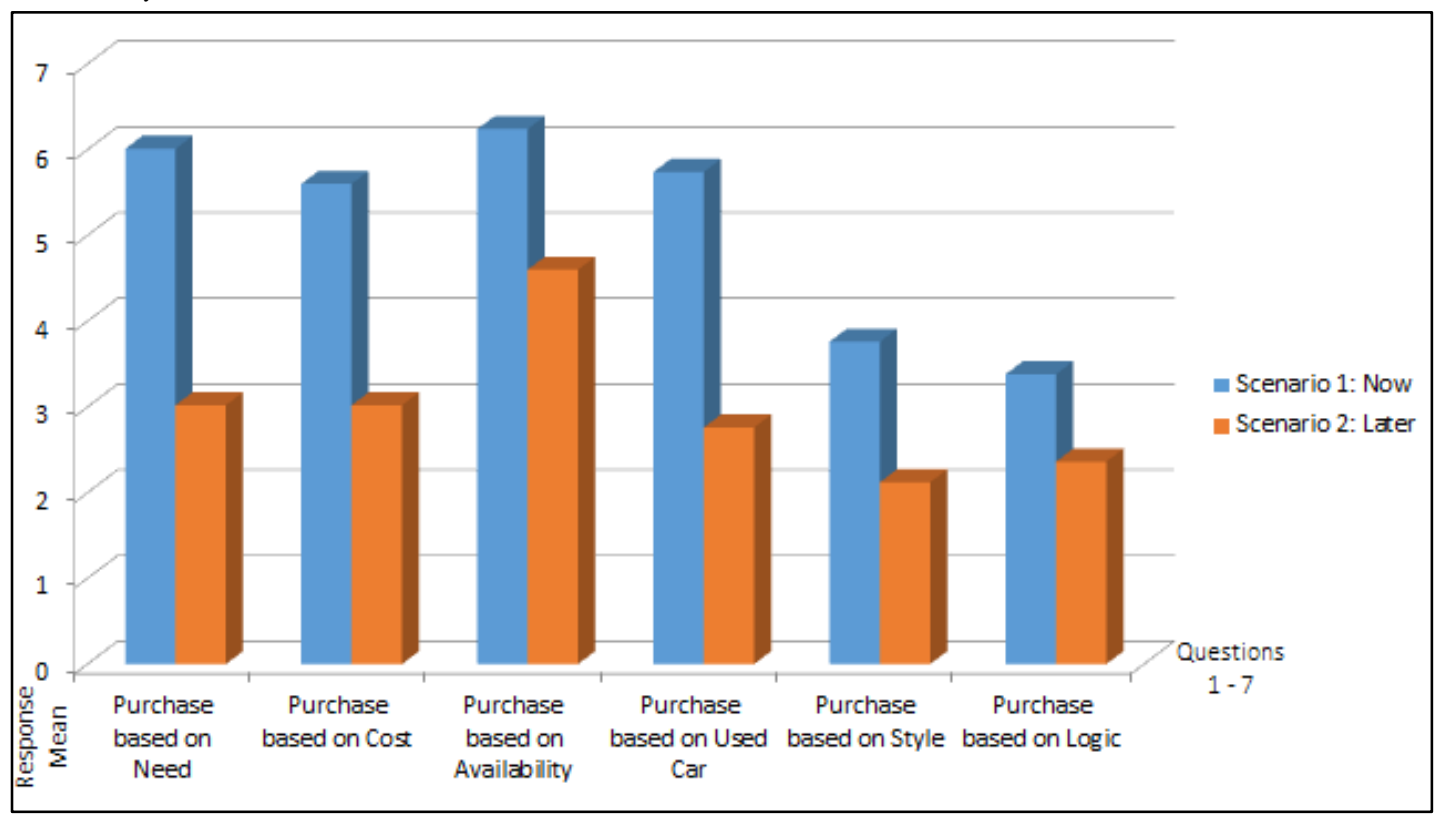

Graph 1: Comparing Means by Purchase Scenario and Criterion

The $T$ statistics in Table 2 below also evidence significant changes in the means, measuring the size of the differences relative to the variation in our sample data, represented in units of standard error; the greater the magnitude of $\mathrm{T}$, the greater the evidence against the null hypothesis which stated that consumer decisions are absolutely rational, and consistently so, over time, and money.

Table 2: Paired Samples T-Test

\begin{tabular}{|c|c|c|c|c|c|c|c|c|c|}
\hline \multirow{2}{*}{ Pair } & Scenario & Mean & \multirow{2}{*}{$\begin{array}{c}\text { Std. } \\
\text { Deviation }\end{array}$} & \multirow{2}{*}{$\begin{array}{c}\text { Std. } \\
\text { Error } \\
\text { Mean }\end{array}$} & $\begin{array}{c}\text { 95\% confiden. } \\
\text { interval of diff. }\end{array}$ & Lower & Upper & df & $\begin{array}{c}\text { Sig. } \\
\text { (2- } \\
\text { tailed) }\end{array}$ \\
\hline Pair 1 & $\begin{array}{c}\text { Purchase 1 vs. 2 based on } \\
\text { Need }\end{array}$ & 3.000 & 1.725 & 0.266 & 2.462 & 3.538 & 11.271 & 41 & 0.000 \\
\hline Pair 2 & $\begin{array}{c}\text { Purchase 1 vs. 2 based on } \\
\text { Cost }\end{array}$ & 2.571 & 1.516 & 0.234 & 2.099 & 3.044 & 10.989 & 41 & 0.000 \\
\hline Pair 3 & $\begin{array}{c}\text { Purchase 1 vs. 2 based on } \\
\text { Availab. }\end{array}$ & 1.643 & 1.543 & 0.238 & 1.162 & 2.124 & 6.899 & 41 & 0.000 \\
\hline Pair 4 & $\begin{array}{c}\text { Purchase 1 vs. 2 based on } \\
\text { Used }\end{array}$ & 2.976 & 1.746 & 0.269 & 2.432 & 3.520 & 11.047 & 41 & 0.000 \\
\hline Pair 5 & $\begin{array}{c}\text { Purchase 1 vs. 2 based on } \\
\text { Style }\end{array}$ & 1.643 & 1.650 & 0.255 & 1.129 & 2.157 & 6.452 & 41 & 0.000 \\
\hline Pair 6 & $\begin{array}{c}\text { Purchase 1 vs. 2 based on } \\
\text { Logic }\end{array}$ & 1.024 & 1.000 & 0.154 & 0.712 & 1.335 & 6.637 & 41 & 0.000 \\
\hline
\end{tabular}

The closer $\mathrm{T}$ is to 0 , the more likely there is no significant difference. Table 2 above shows the greatest difference in certain criteria, like "buy the car I need" vs. "the car I want", followed by "used" vs. "new 
Given the Time and the Money to Think, Consumers will Rely more on Intuition, Sensations, and Emotions, rather than Rationale, to Decide car", for purchase situation number 1 (buying a car upon graduation), and 2 (buying a car later in their professional careers), and, third, for "purchases based on cost or price".

"Availability", "looks and style", and "logic" scored lower on T-values but showing still radically significant differences between means. All significance values scored 0.000 .

\subsection{Most Striking Differences}

The visualizations are striking. On Graph 2 below, purchase scenario 1, buying a car upon graduation, when time and money are scarce, clearly shows a rational decision, leaning toward "the car I need".

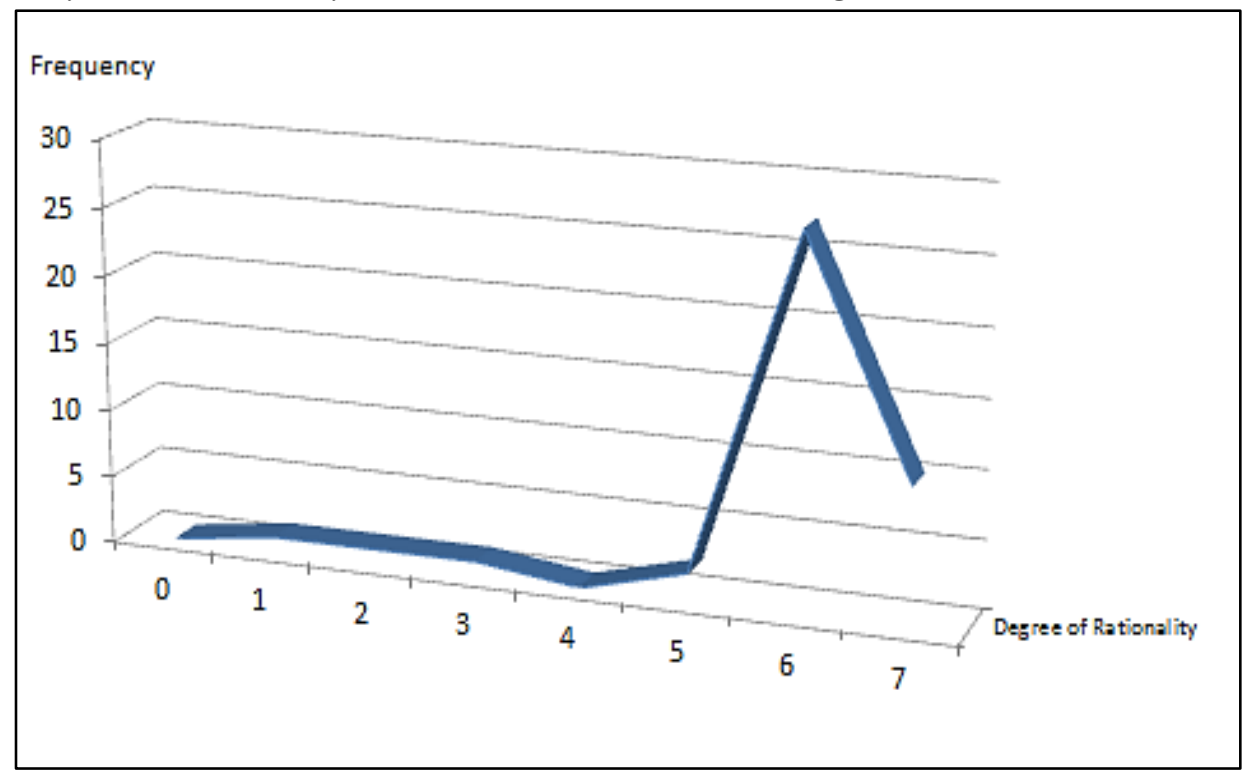

Graph 2: Purchase Scenario 1 based on Need

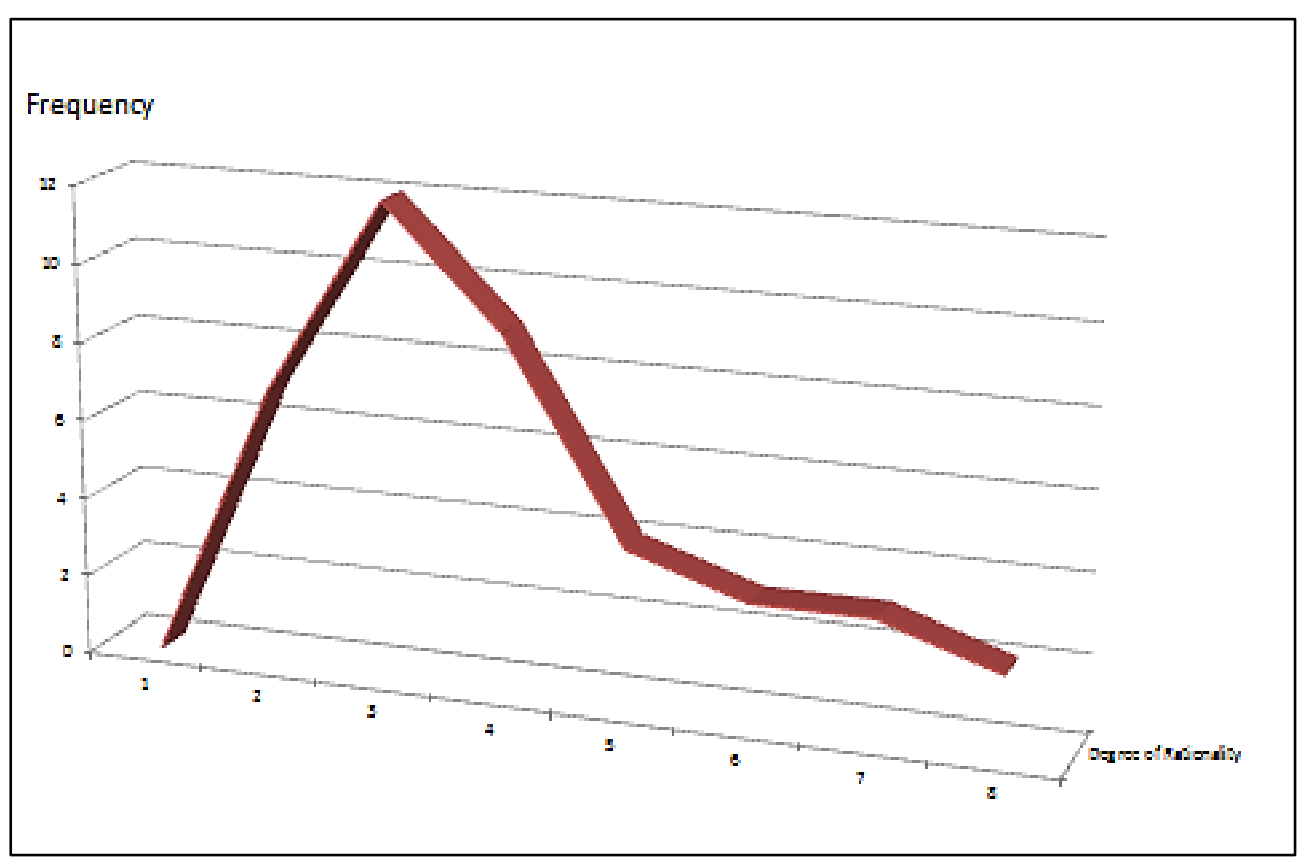

Graph 3: Purchase Scenario 2 based on Need

On Graph 3 above, it can be seen that the curve relating to the need criteria shifts to the left, toward the lower numbers in the scale, that is, from "the car I need" to "the car I want", as consumers transition from one purchase scenario to another, namely, from buying a car upon graduation, when time and money are scarce, to purchasing a car later in their professional careers. 


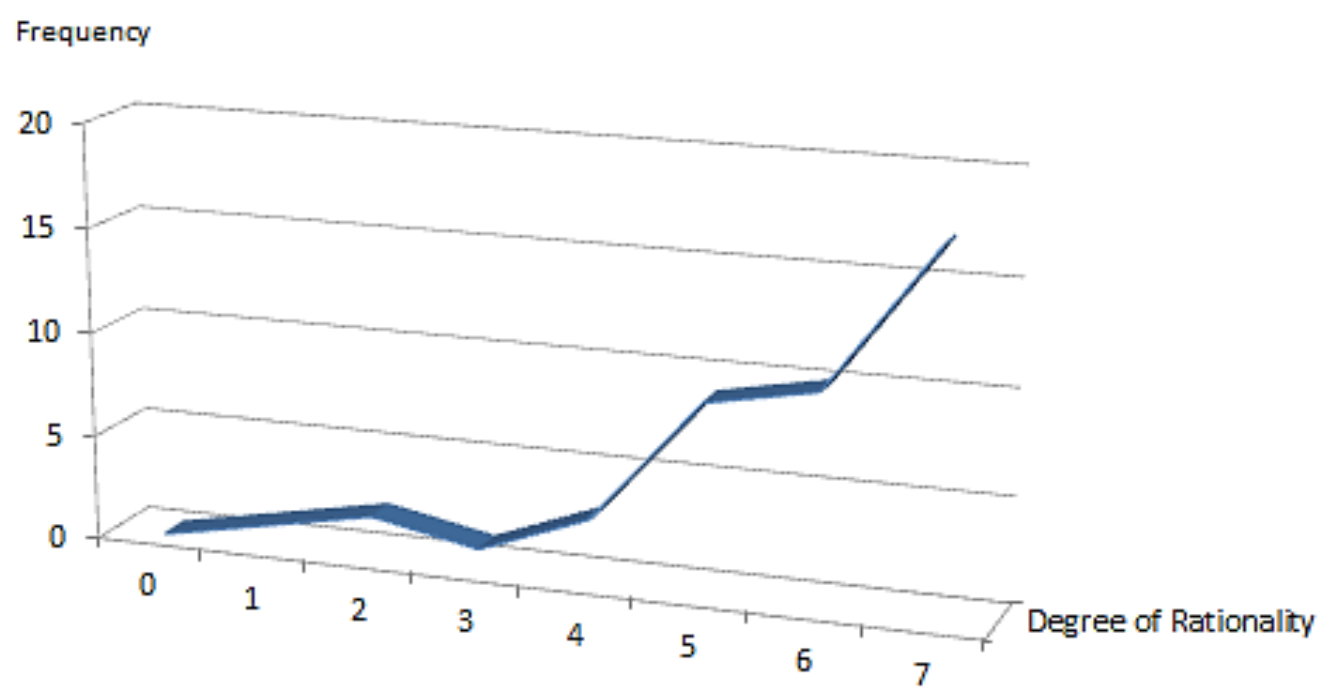

Graph 4: Purchase Scenario 1 based on Used Car (upon graduation)

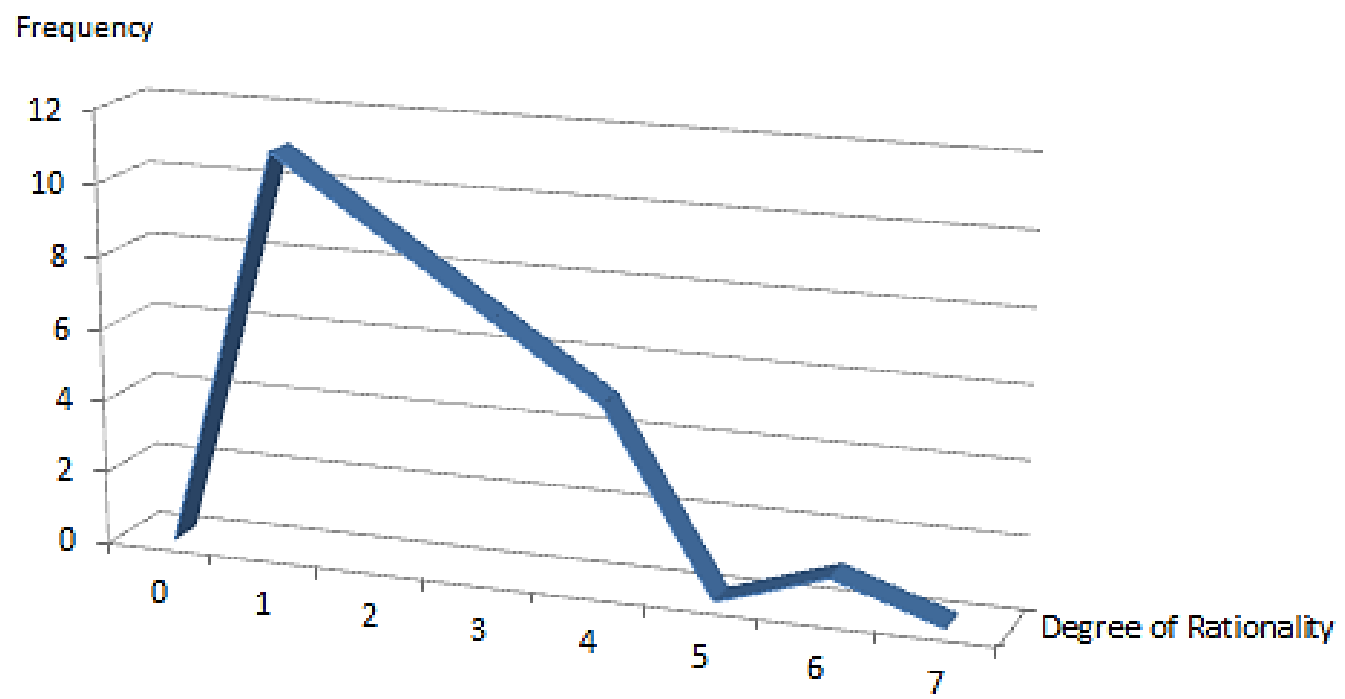

Graph 5: Purchase Scenario 2 based on a New Car (later into their career)

The same happens between Graphs 4 and 5 above, when we transition from a second-hand or used car, the wining tendency upon graduation, toward a new car, which comes out as the preferred option, to be purchased later into their careers, shifting the curve to the left.

\section{Discussion}

We feel there is no decision more important to a young man or woman than buying a car. We contend that this decision will be guided by intuition, emotions, and sensations, when budget and time constraints are removed, and our experiment with Gen $Z$ and millennials proves it. With the passage of time, buying a home will surely be more important. But even then, as Kahneman (2003) found, it is most possible that the same criteria will prevail. Cian, Krishna and Schwartz (2015) say that emotion and rationality are fundamental elements of human life, and they seem to create a continuum, a balance as Fetterman and Robinson (2013) would say, which allows decisions to be more rational or more emotional, depending on the circumstances, that we are not always that rational, then, as Shugan (2006), and Steven (2006) found. 
Indeed, Shelley (2019) seems to be right when she speaks of "the amygdala era", retaking MacLean's (1973) concept of the Triune Brain. As we found here, given the time and the money, consumers, humans, that is, will revert to their primeval instincts and to the somatosensory and emotional experiences that make up their implicit memory to decide.

Not to our surprise, the "follow my nose" criterion did not score high on rationality on either purchase situation, showing a mean of 3.38 over 7 on logic. Nevertheless, it did shift toward emotionality, just the same, on the second scenario, down to 2.36 , for the car to be bought at a later time. It seems as if people will always follow their initial intuitions, and "gut feeling", in decision-making, as Roeser (2010) found, even "against their better judgment", as Denes-Raj and Epstein (1994) suggested. Almost the same outcome was observed on looks and style, with a mean of 3.76 for the car upon graduation, barely on the rational side, if we were to cut in the middle, between 1 and 7 , to create a threshold, vs. a 2.12 for the car to be purchased later on. As Rytel (2010) would say, products project images and symbols which generate sensations and consumers will be guided by these in their decision processes.

The implications and applications of this research are clear. Some marketers may generalize and think that the more important the purchase, like a home or a car, and the more mature the consumer, the more rational the criteria will be; and would stress logic in their communications and sales arguments, following blindly Krugman's (1965) concept of high and low involvement in advertising, and Petty, Cacioppo and Schumann's (1983) model of central vs. peripheral argumentations; and they would be wrong. Given the time and the money, consumers will follow their feelings in their purchase decisions.

\section{Conclusions}

This research manipulated time and money to test how rational or emotional consumer decisions will be given sufficient resources. General wisdom would say that as we age and acquire wealth, our decisions will tend to be more rational and mature. Our experiment points to the opposite, as it proves that given the resources, time and money, consumers will decide based more on intuitive, sensory, and emotional criteria, than on purely rational considerations, extending the theory of self-regulation. Resource scarcity would make us think twice and be more rational. Our research went further and found that the more time and the more money consumers have the more hedonic and intuitive their decisions will be. The shifts of the curves, between rational vs. emotional, sensory or intuitive criteria, from one purchase situation to the other, turned out to be statistically significant, and thus demonstrated the progressively incremental weight of what we call "feelings" on consumer decisions. Although we did not test for moderating factors, prior research has proposed that fear, stress, pain, boredom, and fear-of-failure act as inhibitors to intuitive thinking; and we must mention that age was a constant in our study, as we tested the questionnaire only on Gen Z, and to a lesser degree on millennials in the senior class. Certainly, some constraints must apply to this hypothesis. The greatest implication of these findings point to marketers, who might believe that rationality comes with age and wealth perhaps, and will seek accordingly convincing, rational arguments when facing a mature target, and they would be wrong. In the case of car sales, price, miles per gallon and space, for example, may not be the best appeals to persuade Gen X and baby-boomers, much less to convince successful millennials.

\section{Declaration}

\subsection{Study Limitations}

As mentioned, the questionnaire was administered on a trial basis, as a test of the tool's functionality, but it worked. We propose to perfect the scales, expanding them just enough to improve their measuring capacity of rational, emotional, intuitive, and sensory criteria in consumer decisions, while still applying tested and proven tools. The student sample was small $(\mathrm{n}=86)$, and no control group was used, nor did we test for mediating and moderating factors. 


\subsection{Acknowledgments}

The author wishes to acknowledge the orientations of Dr. Vishal Lala, Lubin School of Business professor at Pace University, in the conduction of this trial.

\subsection{Funding Source}

No funds were received nor requested to carry it out.

\subsection{Competing Interest}

Author declared that no competing interest exist in this research publication.

\subsection{Ethical Approval}

IRB approval was not required as the questionnaire was administered as an extra-credit class assignment without personal information to be revealed, according to the University's guidelines (see https://www.pace.edu/office-of-research/research-protections-IRB-IACUC).

\subsection{Informed Consent}

Informed consent was taken from the respondent.

\section{How to Cite this Article:}

Quevedo, F. (2019). Given the Time and the Money to Think, Consumers will Rely more on Intuition, Sensations, and Emotions, rather than Rationale, to Decide. Advanced Journal of Social Science, 6(1), 38-47. doi: 10.21467/ajss.6.1.38-47

\section{References}

Batoni, F. (2015). Jesucristo Psicoanalista. Editoriales Varias, Caracas, Venezuela, ISBN 9789801281498

Bergqvist, A. and Cowan, R. (2018). Evaluative Perception. First edition. Oxford University Press. ISBN 978-0-19-878605-4.

Bettman, J., Luce, M. and Payne, J. (1998). "Constructive Consumer Choice Processes”. Journal of Consumer Research, 25 (December).

Block, M., Schultz, D., Breiter, H., Blood, A., Calder, B., Chamberlain, L... Fengqing, Z. (2015). Redefining Neuromarketing. American Academy of Advertising Conference Proceedings. 53-63.

Buck R., Anderson E., Chaudhuri A. and Ray I. (2004). Emotion and reason in persuasion: Applying the ARI model and the CASC Scale, Journal of Business Research, 57, (6), 647-656.

Cian, L., Krishna, A. and Schwarz, N. (2015). Positioning Rationality and Emotion: Rationality Is Up and Emotion Is Down. Journal of Consumer Research, 42(4), 632-651.

Chang, H. H. and Tuan Pham, M. (2013). Affect as a Decision-Making System of the Present. Journal of Consumer Research, 40(1), 42.

Chanutl, V., Guibert, N., Rojot, J., Dubois, P. and Jacques, R. G. (2011). Les Limites de la Rationalité Limitée? Un Essai de Réflexion en Sciences de Gestion. Management \& Avenir, (8), 97.

Denes-Raj, V. and Epstein, S. (1994). Conflict between intuitive and rational processing: when people behave against their better judgment. Journal of Personality \& Social Psychology, (5), 819.

Eser, Z. Isin, F.B. and Tolon, M. (2011). Perceptions of Marketing Academics, Neurologists, and Marketing Professionals about Neuromarketing. Journal of Marketing Management, 27(7-8), 854-868.

Fetterman, A. K. and Robinson, M. D. (2013). Do you use your head or follow your heart? Self-location predicts personality, emotion, decision making, and performance. Journal of Personality and Social Psychology, 105(2), 316-334.

Glaser, M. (1995). Measuring Intuition. Research Technology Management, (2), 43.

Harmon-Jones, C., Bastian, B. and Harmon-Jones, E. (2016). The Discrete Emotions Questionnaire: A new tool for measuring state selfreported emotions. PlosONE, 11(8).

Howard, J. A. and Sheth, J. N. (1969). The theory of buyer behavior. New York, 63.

Kahneman, D. (2003). A perspective on judgment and choice: Mapping bounded rationality. American Psychologist, 58(9), 697-720.

Kavalali, Ege T. (2015). The Mechanisms and Functions of Spontaneous Neurotransmitter Release. Nature Reviews Neuroscience (1) 5.

Krugman, H. E. (1966). The measurement of advertising involvement. Public opinion quarterly, 30(4), 583-596.

Lake, C. J., Carlson, J., Rose, A. and Chlevin-Thiele, C. (2019). Trust in name brand assessments: The case of the Myers-Briggs Type Indicator. The Psychologist-Manager Journal, 22(2), 91-107.

Lee, L., Lee, M. P., Bertini, M., Zauberman, G. and Ariely, D. (2015). Money, Time, and the Stability of Consumer Preferences. Journal of Marketing Research (JMR), 52(2), 184-199.

Lees-Maffei, G. (2019). Reading Graphic Design in Cultural Context. Bloomsbury Visual Arts. ISBN 9780857858009

Li, S. (2019). Emotional Appeals in Tourism TV Commercials: A Psycho-Physiological Study. Journal of Hospitality \& Tourism Research.

MacLean, P.D. (1973). A Triune Concept of the Brain and Behavior. published for the Ontario Mental Health Foundation by University of Toronto Press, xii, 165 p. illus. $24 \mathrm{~cm}$. ISBN 0802032990

Morin, C. and Renvoise, P. (2018). The Persuasion Code: How Neuromarketing Can Help You Persuade Anyone, Anywhere, Anytime, John Wiley \& Sons, Hoboken, NJ, ISBN 9781119440765.

Nicosia, F. M. (1966). Consumer decision processes; marketing and advertising implications. Englewood Cliffs, N.J., Prentice-Hall [1966]. 
Given the Time and the Money to Think, Consumers will Rely more on Intuition, Sensations, and Emotions, rather than Rationale, to Decide

McMillan, A. (2014). Mind and Brain: A Critical Appraisal of Cognitive Neuroscience. Journal of the History Of The Behavioral Sciences, 50(1), 112-113.

Mogilner, C. (2010) The pursuit of happiness time, money, and social connection. Psychological Science, 21(9): 1348-1354.

Petty, R. E., Cacioppo, J. T. and Schumann, D. (1983). Central and peripheral routes to advertising effectiveness: The moderating role of involvement. Journal of consumer research, 10(2), 135-146.

Phillips, W. J., Fletcher, J. M., Marks, A. G. and Hine, D. W. (2016). Thinking styles and decision making: A meta-analysis. Psychological Bulletin, 142(3), 260-290.

Roeser, S. (2010). Intuitions, Emotions and Gut Reactions in Decisions about Risks: Towards a Different Interpretation of 'Neuroethics'. Journal of Risk Research, 13(2), 175.

Rytel, T. (2010). Emotional marketing concept: The new marketing shift in the postmodern era. Verslas: teorija ir praktika, (1), $30-38$.

Saini, R. and Monga, A. 2008. How I decide depends on what I spend: use of heuristics is greater for time than for money. Journal of Consumer Research, 34(6): 914-922.

Shelley, M. (2019). The Amygdala Era: Emotion and Experience in Memoir. https://digitalcommons.liberty.edu/honors/874

Simon, H. A. (1987). Making Management Decisions: The Role of Intuition and Emotion. The Academy of Management Executive (19871989), (1). 57.

Srinivasan, T. (1987). An Integrative Approach to Consumer Choice. Advances In Consumer Research, 14(1), 96-100.

Srull, T. K. (1987). Memory, Mood, and Consumer Judgment. Advances in Consumer Research, 14(1), 404-407.

Shugan, S.M. (2006). Are Consumers Rational? Marketing Science. 25(1):1-7; Institute for Operations Research and the Management Sciences (INFORMS).

Steven M. (2006). Editorial: Are Consumers Rational? Experimental Evidence. Marketing Science, (1), 1.

Sweldens, S. (2018) Puppets on a String. ERIM Inaugural Address Series Research in Management, May $18^{\text {th }}, 2018$.

Valente, M. (2012). Evolutionary demand: a model for boundedly rational consumers. Journal of Evolutionary Economics, 22(5), 1029.

Zajonc, R.B. and Markus, H. (1982). Affective and Cognitive Factors in Preferences. Journal of Consumer Research, 9(2), 123-131.

Vohs, K. and Faber, R. (2003). Self-Regulation and Impulsive Spending Patterns. Advances in Consumer Research, 30(1), 125-126.

West, P. M., Brockett, P. L. and Golden, L. L. (1997). A comparative analysis of neural networks and statistical methods for predicting consumer choice. Marketing Science, 16(4), 370.

Publish your research article in AIJR journals-

$\checkmark \quad$ Online Submission and Tracking

$\checkmark \quad$ Peer-Reviewed

$\checkmark \quad$ Rapid decision

$\checkmark \quad$ Immediate Publication after acceptance

$\checkmark \quad$ Articles freely available online

$\checkmark \quad$ Retain full copyright of your article.

Submit your article at journals.aijr.in
Publish your books with AIJR publisher-

Publish with ISBN and DOI.

Publish Thesis/Dissertation as Monograph.

Publish Book Monograph.

Publish Edited Volume/ Book.

Publish Conference Proceedings

Retain full copyright of your books.

Submit your manuscript at books.aijr.org 